\title{
A Comparative Evaluation of Public Road Transportation Systems in India Using Multicriteria Decision-Making Techniques
}

\author{
Anand Kumar $\mathbb{D}$, Gurmeet Singh $(\mathbb{D}$, and Omkarprasad S. Vaidya
}

Indian Institute of Management, Lucknow 226013, Uttar Pradesh, India

Correspondence should be addressed to Omkarprasad S. Vaidya; osv@iiml.ac.in

Received 3 March 2020; Revised 14 September 2020; Accepted 23 September 2020; Published 24 October 2020

Academic Editor: Michela Le Pira

Copyright (c) 2020 Anand Kumar et al. This is an open access article distributed under the Creative Commons Attribution License, which permits unrestricted use, distribution, and reproduction in any medium, provided the original work is properly cited.

In this paper, we evaluate the performance of major public road transport organizations in India. The contribution of the paper lies in integrating four multicriteria decision-making ( $\mathrm{MCDM}$ ) techniques to assess the relative performance of public road transportation systems on twenty-three criteria across two consecutive years. The paper classifies the criteria into functional heads and establishes the relative importance of heads using the analytical hierarchical process (AHP). The efficiency scores of each organization referred to as a decision-making unit (DMU) were computed for the classified heads using the Data Envelopment Analysis (DEA) approach. The multicriteria optimization and compromise solution technique "VlseKriterijumska Optimizacija I Kompromisno Resenje" (VIKOR) was used to assign a final rank to each of the DMUs using computed efficiency scores and established weights. Finally, we analyzed the performance of the DMUs across the two consecutive years using the Malmquist Productivity Index (MPI). Our key findings are as follows: First, the performance of all DMUs has improved in the second year with respect to the first year; second, significant improvement is observed in the "expenses" functional head which carries a substantial weight among the functional heads; third, barring few DMUs, the performance of the majority of DMUs has worsened in the "accident" functional head; fourth, while few DMUs have been consistently very good performers in both the years, there are also few DMUs which have consistently performed poorly in both the years. The inferences drawn from the study can be leveraged for future policy formulations by the state government and local municipal corporations and for sharing best practices among the DMUs.

\section{Introduction}

Public road transport organizations are an integral part of the Indian transport sector. While an increasing number of car and two-wheelers contribute to traffic congestion and pollution, the bus-based public road transport services accommodate a larger number of commuters, thereby transporting the maximum number of people per unit of road space and passenger $-\mathrm{km}$ per litre. On an average, the energy consumption of a car is 6 times more than that of a bus, whereas energy consumption of two- and three-wheelers is 2.5 and 4.7 times more than that of a bus, respectively. This highlights the need for the growth of public road transport organizations as a means of mass commuting to meet the transport demand of the country.
Public road transportation organizations require substantial improvements on several fronts to become a preferred choice of commutation for passengers. During 20142015, public road transport organizations in India reported 19076 road accident cases, of which 4129 were fatal accidents [1]. Indian public road organizations lag on bus penetration. The bus penetration in India (1.4 buses per 1000 persons) is much lower as compared to that of other developing countries like Thailand (8.6 buses per 1000 persons), South Africa ( 6.5 buses per 1000 persons), and Mexico (2.8 buses per 1000 persons) [1]. It is suggested that public road transport organizations should modernize the fleet and scrap overaged buses which are necessary to maintain service quality and meet the expectation of passengers.

To become an effective means of mass commutation, it is important that public road transport organizations become 
financially and operationally efficient. The road transport organizations should boost traffic revenue, trim unnecessary expenses, increase operational efficiency, and provide accident-free safe services to the passengers. The best performing road transport organization on each criterion should be identified, benchmarked, and the key learnings should be shared among the organizations. A comprehensive performance evaluation technique needs to be developed which evaluates the relative performance of road transport organizations on multiple criteria and ranks these organizations based on their relative performances.

1.1. Contribution. The objective of the study is to develop a methodology to assess and compare the performance of DMUs on multiple functional criteria, thereby resulting in a comprehensive performance evaluation of the DMUs. The proposed methodology can draw comparisons between intrastate and interstate DMUs operating on different scales and hence can be applied for DMUs belonging to any region, state, or country. The methodology developed can evaluate the performance of a group of DMUs belonging to any common functional domain and thus can be applied widely. The primary contribution of the study lies in integrating the following MCDM techniques: AHP to establish the relative importance of functional heads; DEA to compute the efficiency score of DMUs for each functional head; VIKOR to rank DMUs based on computed efficiency scores and established weights; MPI to assess the performance of DMUs in the second year with respect to their performance in the first year.

To demonstrate the application of the proposed methodology, we evaluate the performance of major public road transport organizations in India, which shall provide state governments and local municipal corporations a base to identify the areas of improvement and make suitable policy amendments to address them. Based on twenty-three criteria spanning two consecutive years, we analyze the relative performance of forty-two public road transport organizations by constituting six functional heads. The best performing DMUs are identified for benchmarking and relative comparison among the DMUs.

The subsequent sections of this paper are organized in the following manner: We start by reviewing the extant literature and then explain briefly the tools used for this study such as AHP, DEA, VIKOR, and MPI. Then, we introduce our proposed methodology followed by results, analysis, and conclusion.

\section{Literature Review}

Many studies have been carried out to evaluate similar performance in different countries/regions. For instance, Annema et al. [2] have critically evaluated two methods of designing an appraisal tool for public transport. They have used two approaches: cost-benefit analysis (CBA) and multicriteria decision-making tools (MCDMTs). They developed a chart to study the trade-off information and suggested a possible approach to incorporate them together.
Pineda et al. [3] have proposed an integrated method to evaluate the operational and financial performance of airlines. They incorporated the data analytics network process (DANP) along with VIKOR to evaluate different airlines in the USA. In this study, we provide an approach that uses MCDMT only, but it incorporates both operational and financial criteria for evaluation.

Many studies for the performance evaluation of transportation systems and other associated areas have been conducted using MCDM techniques. Pérez et al. [4] have presented a review of papers published between 1982 and 2014, which highlights the MCDM techniques being used for decision making in urban public transport systems. Cruz et al. [5] and Holmgren [6] conducted performance evaluation studies in Portugal and Sweden, respectively. While Cruz worked with DEA-based benchmarking models, Holmgren used frontier-based evaluation of efficiency. Similarly, Vaidya [7] and Saxena [8] evaluated road transportation in the Indian context. Vaidya [7] evaluated Indian state/regional transport units using DEA and AHP. He adopted a top-down approach and computed the overall efficiency values to understand the performance of a given transportation unit. Saxena [8] used the DEA approach to formulate a benchmarking strategy for Delhi Transport Corporation. Chakraborty et al. [9] performed a performance evaluation of Indian roads on state-wise data using PROMTHEE_GIS. Ranjan et al. [10] evaluated Indian railway zones using DEMATEL and VIKOR. Some authors have exclusively used DEA for performance evaluation in road transports systems. Hawas et al. [11] and Hahn et al. [12] used DEA exclusively for the evaluation of bus services. These investigations were used to reduce operating costs and make policy decisions like the addition of bus stops and reduction of taxes. Rodrigues et al. [13] evaluated road freight transport performance by developing "extra distance" as a measure for evaluation. In this study, we perform both year-specific relative evaluation (using DEA and VIKOR) and inter-year evaluation (using MPI) of Indian public transport systems.

Some of the recent works have focused on integrating stakeholder involvement with MCDM techniques to support decision making related to transportation. Macharis et al. [14] have proposed multiactor multicriteria analysis (MAMCA) for the evaluation of transport projects; they focus on the inclusion of qualitative as well as quantitative criteria. Ignaccolo et al. [15] have combined AHP with roleplaying games for stakeholder engagement in transport decisions. Ghorbanzadeh et al. [16] have used interval AHP to create a decision support model while considering the involvement of various stakeholder groups in a sustainable urban transport model. Similarly, Moslem et al. [17] have used interval AHP and fuzzy AHP to analyze stakeholder consensus in urban transport development. Giuffrida et al. [18] have carried out a comprehensive literature review of the use of VGI and PPGIS in transport studies and proposed a framework for the evaluation of transport alternatives. They point towards the usefulness of integration between public participation, GIS, and quantitative methods to foster technically sound and shared decisions. Ignaccolo et al. [19] 
have investigated citizen preferences for designing a new transport service using MCDMT. Duleba and Moslem [20] examined the pareto-optimality of the eigenvector obtained from a pairwise comparison matrix in AHP; they applied it to the real data collected from Mersin, Turkey, to gauze the public preference on development of supply quality elements in local bus transportation services. Moslem et al. [21] have integrated a hybrid AHP with BWM to determine significant supply quality criteria for public transportation.

Some authors have tried to use MCDM techniques not only just to evaluate the performance of the public transport system but also to compare it against other modes of transportation. Lopez Lambas and Giuffrida [22] have proposed the use of TOPSIS with GIS to choose between the construction of bus rapid transit (BRT) and light-rail transit (LRT) systems. Nassereddine and Eskandari [23] evaluated the public transport system in Tehran. They proposed a novel MCDM method by integrating DELPHI, GAHP, and PROMETHEE and used it to determine the importance of various means of public transport in Tehran. Garcia Sanchez [24] used DEA, PCA, and Tobit regression for analyzing public bus transport in Spain and concluded that there was no significant difference in the performance of the public transport system against the private transport system. Gonçalves de Carvalho Wolff and Antonio Farah Caldas [25] proposed a transport infrastructure model (TIM) to evaluate Brazilian road transport. Sun et al. [26] have evaluated public transport accessibility in the urban network by using two indices: the supply level of urban public transport and a public transport-private car traveling time ratio.

This study primarily focuses on developing a methodology to evaluate the performance of the DMUs by integrating four MCDM techniques: AHP, DEA, VIKOR, and MPI. The application of the developed methodology is then illustrated by assessing the performance of public road transport organizations in India. The forty-two public road transport organizations are evaluated on twenty-three criteria classified under six functional heads. The performances of these DMUs are analyzed for two consecutive years, i.e., 2014-2015 and 2015-2016, respectively. The public road transport organizations are categorized based on their performance, the best-performing organizations in each year are identified, and improvement in their ranks across the two years is analyzed. This study uses the proposed methodology to compare road transport organizations among peers and identifies the best-performing units to help in policy formulation and sharing of best practices.

\section{Research Method}

In this section, we briefly explain the tools used in this study for the evaluation of performance of DMUs. A schematic representation of the proposed methodology is available in Figure 1. To facilitate the proposed analysis of the DMUs, we need to develop a phase-wise evaluation method using the four techniques we discuss below. The DMUs under consideration are spread across the country operating on different scales with varying size and staff strength. The magnitude of revenue and costs varies largely across DMUs.
Hence, a direct comparison of their absolute numbers will not give accurate performance results; rather, we should focus on comparing the ratio of the output to input of each of the transportation system. Such an analysis is facilitated by DEA, but a number of DMUs may come out with an efficiency score of 1 in DEA. To obtain unique ranking for the DMUs, we use the efficiency scores obtained from DEA as input in VIKOR. Finally, we need to provide some weights to each of the evaluation criteria which is a highly judgemental call, for which we have resorted to AHP. Furthermore, we have also performed a longitudinal comparison of the DMUs to see how their performance has changed over the years; this analysis is facilitated by using Malmquist DEA.

3.1. Analytic Hierarchical Process (AHP). AHP is used to determine the relative importance of the criteria involved in decision making. AHP can be used for both qualitative and quantitative criteria which can be compared to determine relative weights and rankings $[27,28]$. To use AHP, following steps needs to be performed :

(a) Structuring the decision problem: To solve any decision-making problem using AHP, it should be structured into a minimum of three levels as follows:

(i) Level 1 (goal statement): in this study, the goal was to rank the DMUs in the order of their performance.

(ii) Level 2 (criteria definition): DMUs were evaluated on 23 criteria which were classified into 6 functional heads.

(iii) Level 3 (picking the alternatives): this study compared 42 DMUs for ranking the DMUs in terms of their performances.

(b) Pairwise comparison: it is the subjective part of the AHP, wherein comparisons are carried out based on the judgment of area experts. Pairwise comparison results into the decision matrix whose elements consist of relative weights of one criterion over the other. The range of pairwise comparisons is from $1 / 9$ to 9.

(c) Calculation of weights: weights are calculated using the concept of the eigenvector. In this concept, the decision matrix is squared; the sum of the elements of the row is calculated and then normalized. The process must be iterated until the difference between the elements of the two resultant vectors (i.e., the difference in the eigenvector solution) is insignificant. The elements of the last eigenvector solution are the weights of the criteria.

(d) Check for consistency: consistency check is done to check the consistency of judgments. The check for consistency is done using the consistency ratio (CR). If the value of $C R$ exceeds 0.1 , it is inferred that judgments are inconsistent, and the exercise must be repeated. The steps to use AHP are shown in Figure 2. 
AHP

To establish relative importance of

the functional heads

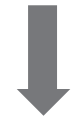

DEA

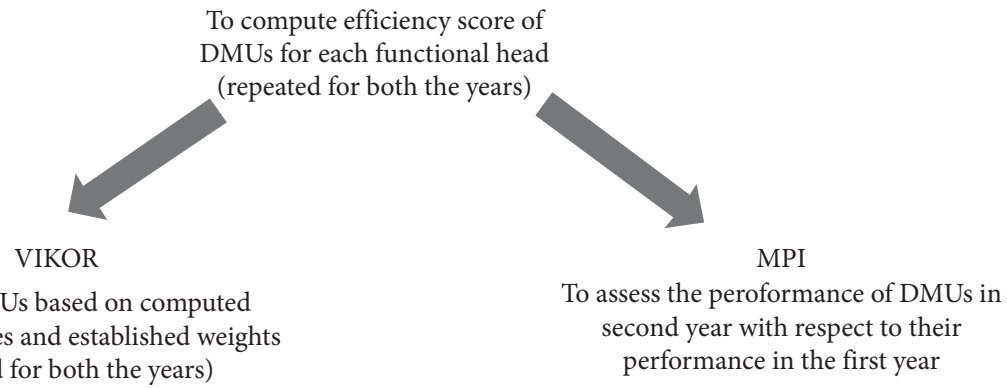

FIGURE 1: Schematic representation of the proposed methodology.

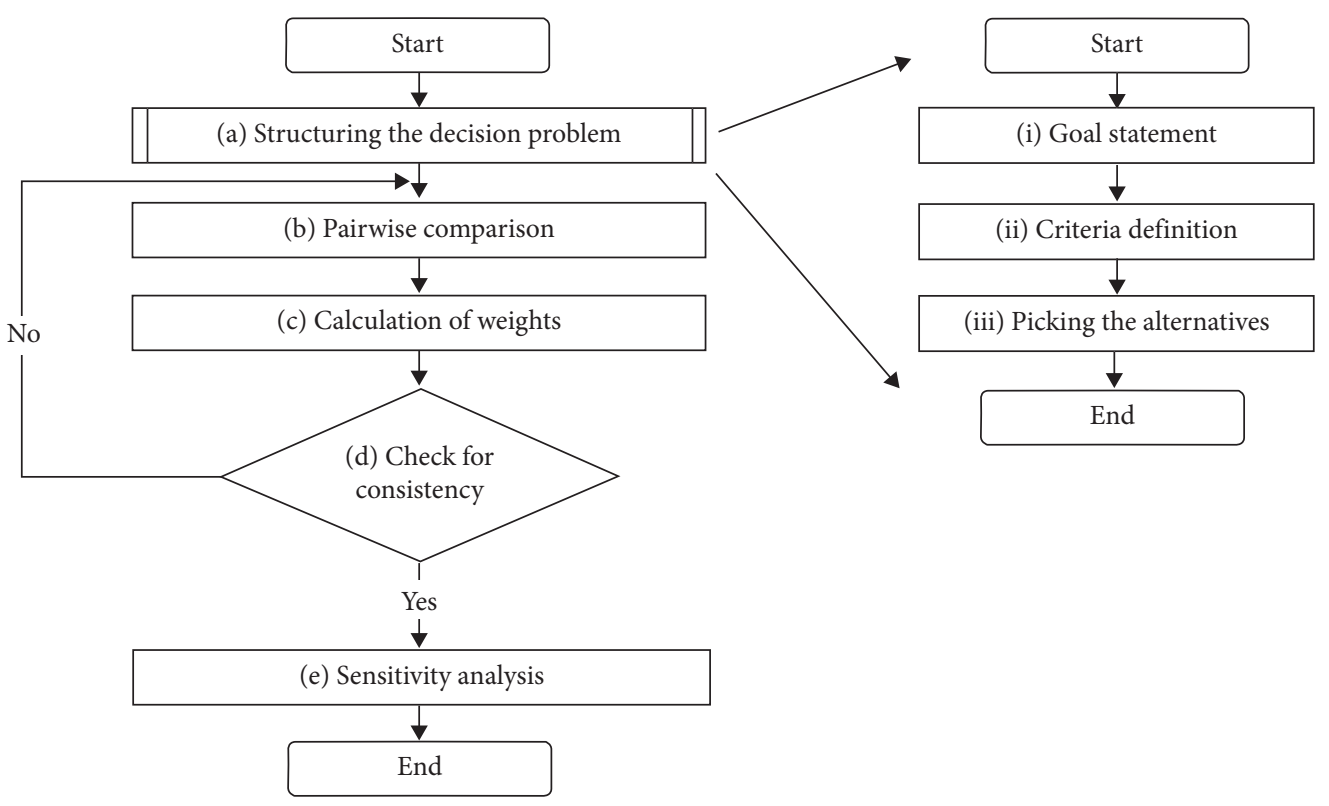

Figure 2: Steps of AHP.

(e) Sensitivity analysis: it is done to check the stability of the final result and identify the functional heads which are most critical to the results. We adopt the absolute top (AT) method given by Triantaphyllou and Sanchez [29]. AT is defined as the smallest change in the weight of criteria which will result in a change in the rank of the topmost DMU.

3.2. Data Envelopment Analysis (DEA). The DEA concept was initially conceived by Farrell [30] for evaluating the US government program in the education sector. Later, Charnes et al. [31] developed the model which came to be known as the CCR DEA model. DEA is a performance measurement technique based on linear programming and is used for calculating the efficiencies of DMUs. The performance of a DMU is determined through efficiency which is defined as the ratio of total weighted outputs to total weighted inputs.

The efficiency of DMUs in DEA is measured relative to an efficiency frontier which is built by connecting the bestperforming DMUs. The best-performing DMUs/efficient DMUs are allocated an efficiency score of 1 (100\%) and lie on the frontier. Other DMUs whose efficiency score is less than 1 lie inside the frontier. None of the DMUs shall lie out of the frontier since the efficiency score of greater than 1 is not feasible. The notations and equations used in the formulation of DEA for the $m^{\text {th }}$ DMU are the following: 


$$
\begin{aligned}
\max \eta_{m}= & \sum_{j=1}^{j} V_{j m} Y_{j m} \\
\text { s.t. } & \sum_{j=1}^{j} U_{j m} X_{j m}=1 \\
& \sum_{j=1}^{j} V_{j m} Y_{j n}-\sum_{j=1}^{j} U_{j m} X_{j n} \leq 0, \\
& V_{j m}, U_{i m} \geq 0, \quad \forall i=1,2, \ldots, I, j=1,2, \ldots, J,
\end{aligned}
$$

where $\eta_{m}$ is the efficiency of the $m^{\text {th }}$ DMU, $Y_{j m}$ is the $j^{\text {th }}$ output of the $m^{\text {th }}$ DMU, $V_{j m}$ is the weight of the $j^{\text {th }}$ output, $X_{i m}$ is the $i^{\text {th }}$ input of the $m^{\text {th }}$ DMU, $U_{i m}$ is the weight of the $i^{\text {th }}$ input, and $Y_{j n}$ and $X_{i n}$ are the $j^{\text {th }}$ output and $i^{\text {th }}$ input of the $n^{\text {th }}$ DMU.

\subsection{Multicriteria Optimization and Compromise Solution} (VIKOR). The initial concepts of VIKOR were developed by Opricovic S. with its application published by Duckstein and Opricovic [32]. The VIKOR method computes the utility and regret parameters for each of the DMUs. The VIKOR method results in 3 scores for each DMU: overall score $(Q)$, utility score $(S)$, and regret score $(R)$. The overall score is computed by assigning equal weights to the utility and regret scores. The variables and equations used for calculation of the score as given by Opricovic and Tzeng [33] in their comparative analysis of TOPSIS and VIKOR are as follows:

$$
\begin{aligned}
& S_{j}=\sum_{i=1}^{n} \frac{w_{i}\left(f_{i}^{*}-f_{i j}\right)}{\left(f_{i}^{*}-f_{i}^{-}\right)}, \\
& R_{j}=\max _{i} \frac{w_{i}\left(f_{i}^{*}-f_{i j}\right)}{\left(f_{i}^{*}-f_{i}^{-}\right)}, \\
& Q_{j}=\frac{v\left(S_{j}-S^{*}\right)}{\left(S^{-}-S^{*}\right)}+\frac{(1-v)\left(R_{j}-R^{*}\right)}{\left(R^{-}-R^{*}\right)},
\end{aligned}
$$

where $j$ is the number of alternatives, $n$ is the number of criteria, $f_{i j}$ is the value of the $i^{\text {th }}$ criterion function for the alternative $a_{j}, Q_{j}$ is the overall score of the $j^{\text {th }}$ alternative, $S_{j}$ is the utility score of the $j^{\text {th }}$ alternative, $R_{j}$ is the regret score of the $j^{\text {th }}$ alternative, and $v$ is the weight of the majority of criteria.

After obtaining the values of $S, R$, and $Q$, alternatives are ranked by sorting these values in the decreasing order. The results are three ranking lists. A compromise solution, i.e., the alternative $A(1)$, which is the best ranked by the measure $Q$ (minimum) as given in $[34,35]$, is proposed if the following two conditions are satisfied:

(a) Condition of acceptable advantage: when $Q(A(2))-$ $\mathrm{Q}(A(1)) \geq \mathrm{DQ}$, where $\mathrm{DQ}=1 /(j-1)$ and $A(2)$ is the alternative with the second position on the ranking list by $Q$

(b) Condition of acceptable stability in decision making: the alternative $A(1)$ must also be the best ranked by $S$ or/and $R$

If one of the conditions is not satisfied, then a set of compromise solutions is proposed, which consists of the following:

(i) Alternative $A(1)$ and $A(2)$ if only condition (b) is not satisfied, or

(ii) Alternatives $A(1), A(2), \ldots, A(M)$ if condition (a) is not satisfied, where $A(M)$ is determined by the relation $Q(A(M))-Q(A(1))<$ DQ for maximum $M$

3.4. Malmquist Productivity Index (MPI). Malmquist [36] proposed the initial concept of the MPI which was further built upon by many authors. The method of measuring the change in efficiency through the MPI using the DEA frontier was given by Färe et al. [37]. The equivalent way of writing the MPI is given by

$$
\begin{aligned}
M_{o}\left(x^{t+1}, y^{t+1}, x^{t}, y^{t}\right)= & \frac{D_{o}^{t+1}\left(x^{t+1}, y^{t+1}\right)}{D_{o}^{t}\left(x^{t}, y^{t}\right)} \\
& \times\left[\left(\frac{D_{o}^{t}\left(x^{t+1}, y^{t+1}\right)}{D_{o}^{t+1}\left(x^{t+1}, y^{t+1}\right)}\right) \times\left(\frac{D_{o}^{t}\left(x^{t}, y^{t}\right)}{D_{o}^{t+1}\left(x^{t}, y^{t}\right)}\right)\right]^{1 / 2}, \\
\text { efficiency change }= & \frac{D_{o}^{t+1}\left(x^{t+1}, y^{t+1}\right)}{D_{o}^{t}\left(x^{t}, y^{t}\right)}, \\
\text { technical change }= & {\left[\left(\frac{D_{o}^{t}\left(x^{t+1}, y^{t+1}\right)}{D_{o}^{t+1}\left(x^{t+1}, y^{t+1}\right)}\right) \times\left(\frac{D_{o}^{t}\left(x^{t}, y^{t}\right)}{D_{o}^{t+1}\left(x^{t}, y^{t}\right)}\right)\right]^{1 / 2}, }
\end{aligned}
$$

where $x^{t}$ is the input at time $t, y^{t}$ is the output at time $t, M_{o}$ is the output-based Malmquist productivity change index, and $D_{o}^{t}\left(x^{t}, y^{t}\right)$ is the output distance function at time $t$.

The value of $M_{o}$ should be interpreted as follows:

$M_{o}>1$ indicates that efficiency has increased over the earlier period

$M_{o}<1$ indicates that efficiency has decreased over the earlier period

$M_{o}=1$ indicates no change in the efficiency

In this study, $M_{o}$ is applied to compare the efficiencies of DMUs across two years on each of the six functional heads. 
We use these tools in a phased manner to perform the evaluation of the DMUs; the same has been elaborated in detail in the subsequent section.

\section{Results}

In this section, we explain the computational details of the analyses and show the subsequent results. The DMUs used in this study were the state/municipal run road transport corporations (Appendix A of Supplementary Material (available here)). The required data were taken from a report published by the Ministry of Road Transport and Highways, Government of India [1]. The data used were for two consecutive years: 2014-2015 and 2015-2016 (Tables B1 and B2 in Appendix B of Supplementary Material). The various input and output criteria for different functional heads used in DEA are briefly described in Appendix C of Supplementary Material.

4.1. Phase-Wise Performance Evaluation. The evaluation of the relative performance of the transportation system has been carried out in the following four phases.

4.1.1. Phase 1. In phase 1, AHP was used to determine the relative weights of the 6 functional heads: accident, traffic revenue, expenses, vehicle operations, manpower operations, and maintenance. A team of 5 experts provided their pairwise judgments. 2 experts were regular commuters of public transport, one expert was from the strategic team of an organization involved, one expert was from an operational team of an organization, and one expert was an academician. All the experts were at least a graduate and had three years of work experience. A questionnaire was given to all the experts to rate the importance of each of the criteria. Furthermore, discussions were held with the experts to form a pairwise comparison matrix for the functional heads under consideration. A consolidated pairwise comparison obtained as per requirements of group decision making (geometric mean) of the functional heads is shown in Table 1. The weights assigned to functional heads were accident (0.084), traffic revenue (0.258), expenses (0.258), vehicle operations (0.136), manpower (0.154), and maintenance (0.109) (Tables 2 and 3 ).

The consistency check for the pairwise comparison was done by calculating the consistency index (CI) and consistency ratio (CR). The value of CI was 0.014 and $\mathrm{CR}$ was 0.011 (less than 0.1 ), thereby ensuring consistency in the pair-wise judgments.

4.1.2. Phase 2. In this phase, single-stage input-oriented CCR DEA was used to compute the efficiency of functional heads of all the DMUs. It is to be noted that few functional heads like accident, expenses, and maintenance were of lower the better type. To accommodate this, Ali and Seiford [38] computed the efficiencies by considering the $\mathrm{TR}_{\beta}$ approach. In this approach, a large, scalar $\beta$ was added to each of the undesirable output values such that the transformed values are positive. This transformation follows the expression:

$$
f_{r j}(q)=-q_{r j}+\beta_{r}
$$

where $r$ is the output, $j$ is the DMU, $q$ is the undesirable output value, and $f(q)$ is the desired transformed value.

For computing the efficiency value of each of the DMU, we have used the DEAP 2.1 computer program developed by the Centre for Efficiency and Productivity Analysis, University of Queensland, Brisbane, Australia. Other methods/ tools like excel solver can be used for the same. DEAP 2.1 has been used because of its ease of use and accessibility. The details of the software can be found in [39].

4.1.3. Phase 3. In the third phase of the study, the VIKOR method was applied to obtain the overall score of each of the DMUs. The weights and efficiency values used in VIKOR were those obtained in the first phase and second phase, respectively. The efficiency values were used to construct a decision matrix which acts as an input for the VIKOR method of ranking the alternatives. Ranks were awarded in the descending order of the score with the best performer having the minimum score.

4.1.4. Phase 4. The MPI was computed in the last phase, which measures the total factor productivity change between the two periods. It was applied to check whether the efficiency of DMUs has increased, decreased, or remained the same over the two years.

4.2. Performance Results of 2014-2015. The final ranks of DMUs based on the $Q$ score are shown in Table 2. The DMUs can be identified from their serial number (Sr. No. of the DMU) using Appendix A of Supplementary Material.

From Table 2, we realize Thane MT (DMU Sr. No. 35), Navi Mumbai MT (DMU Sr. No. 22), and Odisha SRTC (DMU Sr. No. 26) ranked 1, 2, and 3, respectively, among the DMUs. Similarly, Gujarat SRTC (DMU Sr. No. 11), Telangana SRTC (DMU Sr. No. 34), and South Bengal STC (DMU Sr. No. 32) ranked the last among the DMUs with ranks 40,41 , and 42 , respectively. It is important to note that the best performer with rank 1 has the least $Q$ score and the last ranked DMU (rank 42) has the highest $Q$ score.

4.2.1. Analyses for 2014-2015. Based on the $Q$ score (obtained as an output of VIKOR), we have classified the DMUs into five categories: very good performers, good performers, average performers, modest performers, and poor performers (Table 4).

The very good performers like Thane MT and Navi Mumbai MT have been implementing some innovative initiatives to improve their efficiency. Thane MT had launched a mobile app that allows tracking the location of the running buses, booking of tickets, and monthly passes. It led to more customers availing their service and a boost in revenue. Navi Mumbai MT had added e-buses to its fleet discarding some of the old buses which led to a reduction in 
TABle 1: Pairwise comparison of the functional heads.

\begin{tabular}{lcccccc}
\hline & Accident & Traffic revenue & Expenses & Vehicle operations & Manpower & Maintenance \\
\hline Accident & 1.00 & 0.33 & 0.33 & 0.50 & 2.00 & 0.50 \\
Traffic revenue & 3.00 & 1.00 & 1.00 & 2.00 & 2.00 & 2.00 \\
Expenses & 3.00 & 1.00 & 1.00 & 1.00 & 1.00 & 2.00 \\
Vehicle operations & 2.00 & 0.50 & 0.50 & 1.00 & 1.00 & 1.00 \\
Manpower & 2.00 & 0.50 & 0.50 & 1.00 & 0.50 & 2.00 \\
Maintenance & 1.00 & 0.50 & 0.50 & & 1.00 \\
\hline
\end{tabular}

TABle 2: Efficiency and Q score for the DMUs (year 2014-2015).

\begin{tabular}{|c|c|c|c|c|c|c|c|c|c|c|}
\hline $\begin{array}{l}\text { Sr. No. of the } \\
\text { DMU } \\
\text { Weights }\end{array}$ & $\begin{array}{c}\text { Accident } \\
0.084\end{array}$ & $\begin{array}{c}\text { Traffic } \\
\text { revenue } \\
0.258\end{array}$ & $\begin{array}{c}\text { Expenses } \\
0.258\end{array}$ & $\begin{array}{c}\text { Vehicle } \\
\text { operations } \\
0.136\end{array}$ & $\begin{array}{c}\text { Manpower } \\
0.154\end{array}$ & $\begin{array}{c}\text { Maintenance } \\
0.109\end{array}$ & $\begin{array}{l}\text { Utility } \\
\text { score }\end{array}$ & $\begin{array}{l}\text { Regret } \\
\text { score }\end{array}$ & $\begin{array}{c}Q \\
\text { value }\end{array}$ & Rank \\
\hline 1 & 0.879 & 1.000 & 0.739 & 0.941 & 0.791 & 0.643 & 0.288 & 0.134 & 0.496 & 20 \\
\hline 2 & 0.596 & 1.000 & 0.539 & 1.000 & 0.952 & 0.539 & 0.400 & 0.237 & 0.788 & 39 \\
\hline 3 & 1.000 & 1.000 & 1.000 & 1.000 & 1.000 & 0.585 & 0.073 & 0.073 & 0.202 & 5 \\
\hline 4 & 1.000 & 1.000 & 0.998 & 0.841 & 0.286 & 0.909 & 0.229 & 0.128 & 0.437 & 15 \\
\hline 5 & 0.573 & 1.000 & 0.926 & 1.000 & 0.913 & 0.379 & 0.240 & 0.109 & 0.409 & 12 \\
\hline 6 & 0.584 & 1.000 & 0.582 & 1.000 & 1.000 & 0.527 & 0.373 & 0.215 & 0.723 & 34 \\
\hline 7 & 1.000 & 0.755 & 0.799 & 1.000 & 0.707 & 0.472 & 0.390 & 0.141 & 0.593 & 29 \\
\hline 8 & 1.000 & 1.000 & 1.000 & 1.000 & 0.484 & 0.890 & 0.112 & 0.093 & 0.272 & 7 \\
\hline 9 & 1.000 & 1.000 & 1.000 & 1.000 & 1.000 & 0.608 & 0.069 & 0.069 & 0.191 & 4 \\
\hline 10 & 0.532 & 1.000 & 0.916 & 1.000 & 0.723 & 0.477 & 0.269 & 0.092 & 0.400 & 11 \\
\hline 11 & 0.699 & 0.876 & 0.641 & 0.868 & 0.414 & 0.650 & 0.547 & 0.185 & 0.807 & 40 \\
\hline 12 & 0.979 & 0.974 & 0.938 & 0.937 & 0.378 & 0.938 & 0.207 & 0.112 & 0.387 & 10 \\
\hline 13 & 0.984 & 1.000 & 0.878 & 1.000 & 0.472 & 0.407 & 0.265 & 0.105 & 0.421 & 14 \\
\hline 14 & 0.992 & 0.854 & 1.000 & 0.742 & 0.924 & 0.647 & 0.297 & 0.136 & 0.508 & 21 \\
\hline 15 & 0.776 & 1.000 & 0.730 & 0.927 & 0.499 & 0.730 & 0.355 & 0.139 & 0.561 & 26 \\
\hline 16 & 0.587 & 1.000 & 0.630 & 1.000 & 0.575 & 0.452 & 0.438 & 0.190 & 0.728 & 35 \\
\hline 17 & 0.681 & 1.000 & 0.630 & 1.000 & 0.696 & 0.651 & 0.364 & 0.190 & 0.668 & 32 \\
\hline 18 & 1.000 & 0.694 & 1.000 & 1.000 & 1.000 & 1.000 & 0.176 & 0.176 & 0.484 & 19 \\
\hline 19 & 0.702 & 1.000 & 0.707 & 1.000 & 1.000 & 0.527 & 0.288 & 0.151 & 0.528 & 23 \\
\hline 20 & 1.000 & 0.550 & 1.000 & 1.000 & 0.799 & 1.000 & 0.294 & 0.258 & 0.742 & 37 \\
\hline 21 & 1.000 & 0.675 & 0.977 & 0.967 & 0.639 & 0.812 & 0.314 & 0.186 & 0.619 & 30 \\
\hline 22 & 1.000 & 1.000 & 1.000 & 1.000 & 1.000 & 0.760 & 0.042 & 0.042 & 0.117 & 2 \\
\hline 23 & 0.891 & 0.894 & 0.712 & 1.000 & 0.824 & 0.521 & 0.345 & 0.148 & 0.570 & 27 \\
\hline 24 & 0.706 & 1.000 & 0.590 & 0.945 & 0.549 & 0.554 & 0.452 & 0.211 & 0.780 & 38 \\
\hline 25 & 0.656 & 1.000 & 0.594 & 0.994 & 0.729 & 0.553 & 0.401 & 0.209 & 0.734 & 36 \\
\hline 26 & 0.944 & 1.000 & 1.000 & 0.946 & 1.000 & 0.702 & 0.091 & 0.053 & 0.177 & 3 \\
\hline 27 & 0.580 & 1.000 & 0.656 & 1.000 & 0.677 & 0.396 & 0.417 & 0.177 & 0.686 & 33 \\
\hline 28 & 0.657 & 1.000 & 0.697 & 1.000 & 1.000 & 0.458 & 0.313 & 0.156 & 0.559 & 25 \\
\hline 29 & 0.698 & 1.000 & 0.756 & 1.000 & 0.266 & 0.598 & 0.383 & 0.132 & 0.571 & 28 \\
\hline 30 & 0.830 & 0.945 & 0.746 & 0.943 & 0.518 & 0.752 & 0.353 & 0.131 & 0.543 & 24 \\
\hline 31 & 1.000 & 0.853 & 1.000 & 1.000 & 0.572 & 0.579 & 0.236 & 0.084 & 0.357 & 9 \\
\hline 32 & 0.822 & 0.683 & 0.774 & 0.760 & 0.523 & 0.628 & 0.608 & 0.182 & 0.852 & 42 \\
\hline 33 & 0.826 & 1.000 & 0.779 & 1.000 & 0.504 & 0.780 & 0.273 & 0.114 & 0.445 & 16 \\
\hline 34 & 0.582 & 1.000 & 0.498 & 1.000 & 1.000 & 0.487 & 0.424 & 0.258 & 0.848 & 41 \\
\hline 35 & 1.000 & 1.000 & 1.000 & 1.000 & 1.000 & 1.000 & 0.000 & 0.000 & 0.000 & 1 \\
\hline 36 & 0.899 & 1.000 & 0.688 & 1.000 & 0.986 & 0.539 & 0.262 & 0.160 & 0.527 & 22 \\
\hline 37 & 1.000 & 1.000 & 1.000 & 1.000 & 1.000 & 0.546 & 0.080 & 0.080 & 0.221 & 6 \\
\hline 38 & 1.000 & 1.000 & 0.814 & 1.000 & 1.000 & 0.575 & 0.171 & 0.096 & 0.326 & 8 \\
\hline 39 & 1.000 & 1.000 & 0.763 & 1.000 & 1.000 & 0.483 & 0.213 & 0.122 & 0.411 & 13 \\
\hline 40 & 1.000 & 1.000 & 0.589 & 1.000 & 1.000 & 0.556 & 0.290 & 0.211 & 0.648 & 31 \\
\hline 41 & 1.000 & 1.000 & 1.000 & 1.000 & 0.144 & 0.844 & 0.182 & 0.154 & 0.448 & 17 \\
\hline 42 & 1.000 & 1.000 & 0.706 & 1.000 & 1.000 & 0.706 & 0.203 & 0.151 & 0.460 & 18 \\
\hline
\end{tabular}

the maintenance costs. Similarly, Chandigarh TU had introduced electric buses and also a panic button (pressing which will send a message to the control room) in their buses to enhance the safety of women passengers.
We also identified the efficient DMUs in each functional head. The most efficient DMUs (efficient in 5 functional heads or more) are shown in Table 5 with the corresponding functional head in which they are efficient. From Table 5, we 
TABle 3: Efficiency and Q score for the DMUs (year 2015-2016).

\begin{tabular}{|c|c|c|c|c|c|c|c|c|c|c|}
\hline $\begin{array}{l}\text { Sr. no. of the } \\
\text { DMU } \\
\text { Weights }\end{array}$ & $\begin{array}{c}\text { Accident } \\
0.084\end{array}$ & $\begin{array}{c}\text { Traffic } \\
\text { revenue } \\
0.258\end{array}$ & $\begin{array}{c}\text { Expenses } \\
0.258\end{array}$ & $\begin{array}{c}\text { Vehicle } \\
\text { operations } \\
0.136\end{array}$ & $\begin{array}{c}\text { Manpower } \\
0.154\end{array}$ & $\begin{array}{c}\text { Maintenance } \\
0.109\end{array}$ & $\begin{array}{l}\text { Utility } \\
\text { score }\end{array}$ & $\begin{array}{l}\text { Regret } \\
\text { score }\end{array}$ & $\begin{array}{c}Q \\
\text { value }\end{array}$ & Rank \\
\hline 1 & 1.000 & 1.000 & 1.000 & 0.979 & 0.887 & 1.000 & 0.033 & 0.023 & 0.050 & 3 \\
\hline 2 & 0.660 & 1.000 & 0.512 & 1.000 & 0.921 & 0.483 & 0.403 & 0.245 & 0.855 & 5 \\
\hline 3 & 1.000 & 1.000 & 1.000 & 1.000 & 1.000 & 0.707 & 0.049 & 0.049 & 0.117 & 37 \\
\hline 4 & 1.000 & 1.000 & 0.914 & 0.867 & 0.251 & 0.768 & 0.301 & 0.154 & 0.573 & 23 \\
\hline 5 & 0.487 & 1.000 & 0.963 & 1.000 & 0.785 & 0.345 & 0.256 & 0.109 & 0.440 & 30 \\
\hline 6 & 0.488 & 1.000 & 0.659 & 1.000 & 0.852 & 0.450 & 0.377 & 0.171 & 0.681 & 14 \\
\hline 7 & 1.000 & 0.774 & 0.767 & 1.000 & 0.863 & 0.450 & 0.347 & 0.117 & 0.543 & 20 \\
\hline 8 & 1.000 & 0.986 & 1.000 & 0.750 & 0.395 & 1.000 & 0.253 & 0.124 & 0.467 & 16 \\
\hline 9 & 1.000 & 1.000 & 1.000 & 1.000 & 1.000 & 0.584 & 0.070 & 0.070 & 0.178 & 6 \\
\hline 10 & 0.494 & 1.000 & 1.000 & 1.000 & 0.718 & 0.447 & 0.233 & 0.092 & 0.383 & 10 \\
\hline 11 & 0.714 & 0.957 & 0.585 & 0.846 & 0.492 & 0.585 & 0.524 & 0.208 & 0.899 & 40 \\
\hline 12 & 0.822 & 1.000 & 0.764 & 0.935 & 0.480 & 0.764 & 0.325 & 0.118 & 0.525 & 19 \\
\hline 13 & 0.889 & 1.000 & 0.822 & 1.000 & 0.370 & 0.483 & 0.323 & 0.130 & 0.546 & 21 \\
\hline 14 & 0.867 & 0.839 & 0.977 & 0.720 & 0.839 & 0.743 & 0.324 & 0.136 & 0.559 & 22 \\
\hline 15 & 0.724 & 1.000 & 0.628 & 0.925 & 0.557 & 0.619 & 0.423 & 0.186 & 0.757 & 34 \\
\hline 16 & 0.634 & 1.000 & 0.648 & 1.000 & 0.598 & 0.487 & 0.405 & 0.176 & 0.719 & 33 \\
\hline 17 & 0.691 & 1.000 & 0.615 & 1.000 & 0.720 & 0.608 & 0.367 & 0.193 & 0.716 & 32 \\
\hline 18 & 1.000 & 0.794 & 1.000 & 1.000 & 1.000 & 0.883 & 0.120 & 0.100 & 0.289 & 8 \\
\hline 19 & 0.608 & 1.000 & 0.634 & 1.000 & 1.000 & 0.472 & 0.336 & 0.183 & 0.666 & 29 \\
\hline 20 & 1.000 & 0.469 & 1.000 & 1.000 & 0.402 & 1.000 & 0.381 & 0.258 & 0.861 & 38 \\
\hline 21 & 1.000 & 0.645 & 0.912 & 1.000 & 0.599 & 0.667 & 0.355 & 0.173 & 0.663 & 28 \\
\hline 22 & 1.000 & 1.000 & 1.000 & 1.000 & 1.000 & 0.941 & 0.010 & 0.010 & 0.000 & 1 \\
\hline 23 & 0.905 & 1.000 & 0.732 & 1.000 & 1.000 & 0.609 & 0.215 & 0.134 & 0.450 & 15 \\
\hline 24 & 0.695 & 0.988 & 0.537 & 0.943 & 0.565 & 0.509 & 0.487 & 0.232 & 0.911 & 42 \\
\hline 25 & 0.614 & 1.000 & 0.510 & 0.989 & 0.804 & 0.476 & 0.442 & 0.246 & 0.895 & 39 \\
\hline 26 & 1.000 & 1.000 & 1.000 & 1.000 & 1.000 & 0.749 & 0.042 & 0.042 & 0.096 & 4 \\
\hline 27 & 0.568 & 1.000 & 0.792 & 1.000 & 0.683 & 0.408 & 0.339 & 0.104 & 0.510 & 25 \\
\hline 28 & 0.705 & 1.000 & 0.654 & 1.000 & 1.000 & 0.523 & 0.302 & 0.173 & 0.613 & 18 \\
\hline 29 & 0.770 & 1.000 & 0.714 & 1.000 & 0.274 & 0.637 & 0.391 & 0.149 & 0.651 & 36 \\
\hline 30 & 0.840 & 0.920 & 0.625 & 0.944 & 0.472 & 0.619 & 0.453 & 0.188 & 0.789 & 11 \\
\hline 31 & 1.000 & 0.947 & 1.000 & 1.000 & 0.432 & 0.719 & 0.190 & 0.117 & 0.390 & 31 \\
\hline 32 & 0.888 & 0.702 & 0.847 & 0.860 & 0.564 & 0.738 & 0.441 & 0.145 & 0.691 & 13 \\
\hline 33 & 0.868 & 1.000 & 0.796 & 1.000 & 0.495 & 0.796 & 0.262 & 0.104 & 0.434 & 27 \\
\hline 34 & 0.587 & 1.000 & 0.485 & 1.000 & 1.000 & 0.427 & 0.422 & 0.258 & 0.900 & 41 \\
\hline 35 & 1.000 & 1.000 & 1.000 & 0.968 & 1.000 & 1.000 & 0.016 & 0.016 & 0.017 & 2 \\
\hline 36 & 0.896 & 1.000 & 0.637 & 1.000 & 1.000 & 0.514 & 0.280 & 0.182 & 0.609 & 24 \\
\hline 37 & 1.000 & 1.000 & 1.000 & 1.000 & 1.000 & 0.494 & 0.085 & 0.085 & 0.223 & 7 \\
\hline 38 & 1.000 & 1.000 & 0.758 & 1.000 & 1.000 & 0.546 & 0.197 & 0.121 & 0.406 & 12 \\
\hline 39 & 1.000 & 1.000 & 0.713 & 1.000 & 1.000 & 0.464 & 0.233 & 0.144 & 0.487 & 17 \\
\hline 40 & 1.000 & 1.000 & 0.518 & 1.000 & 1.000 & 0.500 & 0.325 & 0.242 & 0.773 & 35 \\
\hline 41 & 1.000 & 1.000 & 1.000 & 1.000 & 0.346 & 1.000 & 0.135 & 0.135 & 0.372 & 9 \\
\hline 42 & 1.000 & 1.000 & 0.601 & 1.000 & 1.000 & 0.600 & 0.267 & 0.200 & 0.633 & 26 \\
\hline
\end{tabular}

realize Thane MT (rank 1) and Navi Mumbai MT (rank 2) are efficient in 6 and 5 functional heads, respectively. Only Thane MT (DMU Sr. No. 35) was found to be efficient in all the functional heads, and it was also the most efficient DMUs as per the result of VIKOR analysis (Table 2).

Note other DMUs of Table 5 (Andaman \& Nicobar ST, Chandigarh TU, and TN STC Kumbakonam Ltd.) are efficient in 5 functional heads, but their performance in maintenance functional head is dismal with an efficiency score less than 0.65 (Table 2). Odisha SRTC (rank 3), though efficient in 3 functional heads, yet maintains an efficiency score of 0.944 (accident), 0.946 (vehicle operations), and 0.702 (maintenance) in other functional heads and hence is ranked above the other DMUs (except Thane MT and Navi Mumbai MT) in Table 5.
The set of efficient DMUs for different combinations of functional heads are shown in Table 6 (serial numbers of DMUs are shown in Appendix A of Supplementary Material). Table 6 represents an upper diagonal portion of the $6 \times 6$ matrix of functional heads. For any combination of functional heads (a row and a column) in Table 6, the corresponding cell represents the list of DMUs that are efficient (having an efficiency score of 1) in both the functional heads. For example, a cell of row 1 (accident) and column 3 (expenses) lists the DMUs (3, 8, 9, 18, 20, 22, 31, 35,37 , and 41 ), which are efficient in both the functional heads in the year 2014-2015.

Note that Thane MT (DMU Sr. No. 35) is present in each cell of Table 6, which shows that Thane MT is efficient for any 
TABLE 4: Categorization of DMUs by performance (year 2014-2015).

\begin{tabular}{|c|c|c|}
\hline Status & Q score & DMUs \\
\hline $\begin{array}{l}\text { Very good } \\
\text { performers }\end{array}$ & $0 \leq Q \leq 0.2$ & Thane MT, Navi Mumbai MT, Odisha SRTC, Chandigarh TU \\
\hline Good performers & $0.2<Q \leq 0.4$ & $\begin{array}{c}\text { Andaman \& Nicobar ST, TN STC (Kumbakonam) Ltd., Calcutta STC, TN STC (Madurai) Ltd., Sikkim } \\
\text { NT, Haryana ST, Delhi TC }\end{array}$ \\
\hline $\begin{array}{l}\text { Average } \\
\text { performers }\end{array}$ & $0.4<Q \leq 0.6$ & $\begin{array}{c}\text { BEST Undertaking, TN STC (Salem) Ltd., J\&K SRTC, Assam STC, State Exp.TC TN Ltd., Tripura RTC, } \\
\text { Uttar Pradesh SRTC (P), Meghalaya STC, Ahmedabad MTC, Kadamba TC Ltd., TN STC (Coimbatore) } \\
\text { Ltd., Metro TC (Chennai) Ltd., Rajasthan SRTC, PUNBUS, Karnataka SRTC, North Bengal STC, State } \\
\text { Transport Punjab, Bihar SRTC }\end{array}$ \\
\hline Modest performers & $0.6<Q \leq 0.8$ & $\begin{array}{c}\text { Nagaland ST. TN STC (Villupuram) Ltd., Maharashtra SRTC(P), Pune Mahamandal, Bangalore } \\
\text { Metropolitan TC, Kerala SRTC, North Western Karnataka RT, Mizoram ST, North Eastern Karnataka } \\
\text { RT, Andhra Pradesh SRTC }\end{array}$ \\
\hline Poor performers & $0.8<Q \leq 1$ & Gujarat SRTC, Telangana SRTC, South Bengal STC \\
\hline
\end{tabular}

TABle 5: Functional heads showing efficient DMUs (year 2014-2015).

\begin{tabular}{|c|c|c|c|c|c|c|}
\hline $\mathrm{DMU}$ & Accident & Traffic revenue & Expenses & Vehicle operations & Manpower & Maintenance \\
\hline Andaman \& Nicobar ST & $\checkmark$ & $\checkmark$ & $\checkmark$ & $\checkmark$ & $\checkmark$ & $x$ \\
\hline Chandigarh TU & $\sqrt{ }$ & $\checkmark$ & $\sqrt{ }$ & $\checkmark$ & $\checkmark$ & $x$ \\
\hline Meghalaya STC & $\checkmark$ & $x$ & $\checkmark$ & $\checkmark$ & $\checkmark$ & $\checkmark$ \\
\hline Navi Mumbai MT & $\checkmark$ & $\checkmark$ & $\checkmark$ & $\checkmark$ & $\checkmark$ & $x$ \\
\hline TN STC Kumbakonam Ltd. & $\checkmark$ & $\checkmark$ & $\sqrt{ }$ & $\checkmark$ & $\checkmark$ & $x$ \\
\hline Thane MT & $\checkmark$ & $\checkmark$ & $\checkmark$ & $\checkmark$ & $\checkmark$ & $\checkmark$ \\
\hline
\end{tabular}

TABle 6: Set of efficient DMUs (year 2014-2015).

\begin{tabular}{|c|c|c|c|c|c|c|}
\hline & Accident & Traffic revenue & Expenses & Vehicle operations & Manpower & Maintenance \\
\hline \multirow[t]{5}{*}{ Accident } & $\begin{array}{c}3,4,7,8,9,18 \\
20,21,22,31,35 \\
37,38,39,40,41 \\
42\end{array}$ & $\begin{array}{c}3,4,8,9,22,35,37,38,39 \\
40,41,42\end{array}$ & $\begin{array}{l}3,8,9,18,20 \\
22,31,35,37 \\
41\end{array}$ & $\begin{array}{c}3,7,8,9,18,20,22,31,35 \\
37,38,39,40,41,42\end{array}$ & $\begin{array}{c}3,9,18,22,35,37 \\
38,39,40,42\end{array}$ & $18,20,35$ \\
\hline & Traffic revenue & $\begin{array}{l}1,2,3,4,5,6,8,9,10,13 \\
15,16,17,19,22,24,25 \\
26,27,28,29,33,34,35 \\
36,37,38,39,40,41,42\end{array}$ & $\begin{array}{l}3,8,9,22,26 \\
35,37,41\end{array}$ & $\begin{array}{c}2,3,5,6,8,9,10,13,16,17 \\
19,22,27,28,29,33,34 \\
35,36,37,38,39,40,41,42\end{array}$ & $\begin{array}{c}3,6,9,19,22,26 \\
28,34,35,37,38 \\
39,40,42\end{array}$ & 35 \\
\hline & & Expenses & $\begin{array}{l}3,8,9,14,18 \\
20,22,26,31 \\
\quad 35,37,41\end{array}$ & $\begin{array}{c}3,8,9,18,20,22,31,35,37 \\
41\end{array}$ & $\begin{array}{c}3,9,18,22,26,35 \\
37\end{array}$ & $18,20,35$ \\
\hline & & & $\begin{array}{c}\text { Vehicle } \\
\text { operations }\end{array}$ & $\begin{array}{c}2,3,5,6,7,8,9,10,13,16 \\
17,18,19,20,22,23,27 \\
28,29,31,33,34,35,36,37 \\
38,39,40,41,42\end{array}$ & $\begin{array}{c}3,6,9,18,19,22 \\
28,34,35,37,38 \\
39,40,42\end{array}$ & $18,20,35$ \\
\hline & & & & Manpower & $\begin{array}{c}3,6,9,18,19,22 \\
26,28,34,35,37 \\
38,39,40,42 \\
\text { Maintenance }\end{array}$ & $\begin{array}{c}18,35 \\
18,20,35\end{array}$ \\
\hline
\end{tabular}

two combinations of the functional heads. The result is supported by the observation that Thane MT is efficient in all the six functional heads (Table 5) and hence is efficient for any two combinations of functional heads as seen in Table 6. Similarly, we observe Navi Mumbai MT (DMU Sr. No. 22), which is efficient in 5 functional heads (Table 5) is present in all the functional heads except the maintenance column of Table 6.

The study also identified the "peers" for the underperforming DMUs within each functional head. The term peer refers to a best-practice organization with an efficiency score equal to 1 . A peer (or a combination of peers) may provide a benchmark for relatively less-efficient organizations. A list of some peer DMUs for different functional heads is summarized in Table B3 (Appendix B of Supplementary Material).

4.3. Performance Results of 2015-2016. The final ranks of DMUs based on the $Q$ score are shown in Table 3. The DMUs of Table 3 can be identified from their serial number (Sr. No. 
of DMU) using Appendix A of Supplementary Material. From Table 3, we observe Navi Mumbai MT (DMU Sr. No. 22), Thane MT (DMU Sr. No. 35), and Ahmedabad MTC (DMU Sr. No. 1) ranked 1, 2, and 3, respectively, among the DMUs. Similarly, Gujarat SRTC (DMU Sr. No. 11), Telangana SRTC (DMU Sr. No. 34), and North Eastern Karnataka RT (DMU Sr. No. 24) ranked the last among the DMUs with ranks 40,41 , and 42 , respectively.

4.3.1. Analyses for 2015-2016. Table 7 classifies DMUs based on the $Q$ score for the year 2015-2016 (equivalent to Table 4 for the year 2014-2015). From Tables 4 and 7, we observe Navi Mumbai MT, Thane MT, Odisha SRTC, and Chandigarh TU are the DMUs which performed consistently well and are classified as very good performers in both the years. We realize TN STC (Kumbakonam) Ltd., Sikkim NT, and Delhi TC performed consistently as good performers in both the years. However, there are also DMUs like Gujarat SRTC and Telangana SRTC which are classified as very poor performers in both the years. These poorly performing DMUs required special attention by the respective state governments, and performance enhancement programs should be run to improve their efficiencies on several fronts.

Some of the very good performing DMUs have adopted the best practices like the introduction of electric buses. Odisha SRTC decided to purchase 100 new e-buses to replace the old buses; it also launched the luxury bus services on 11 routes with air-conditioned and GPS-enabled buses. Andaman and Nicobar ST, which is a very good performer in the year 2015-2016, serves one of the most famous tourist location in India and has thus focused on increasing its quality of service by the introduction of luxury buses and unlimited daily travel passes. It has also added a number of electric vehicles to its fleet to cut down on costs.

Table 8 lists the most efficient DMUs (efficient in 5 functional heads or more) for the year 2015-2016 (equivalent to Table 5 for the year 2014-2015). From Table 8, we observe both Navi Mumbai MT (DMU Sr. No. 22) and Thane MT (DMU Sr. No. 35) with ranks 1 and 2, respectively, are efficient in 5 functional heads only. None of the DMU is efficient in all the functional heads. Out of the 7 most efficient DMUs of Table 8, 5 DMUs are inefficient in the maintenance functional head. This observation clearly identifies maintenance as an area of improvement in which even the most efficient DMUs are lagging. Comparing the most efficient DMUs of the year 2015-2016 (Table 8) and year 2014-2015 (Table 5), we realize 5 DMUs (Andaman \& Nicobar ST, Chandigarh TU, Navi Mumbai MT, Thane MT, and TN STC (Kumbakonam) Ltd.) have been the most efficient DMUs in both the years.

Table 9 identifies the set of efficient DMUs for different combinations of functional heads for the year 2015-2016 (equivalent to Table 6 for the year 2014-2015). For example, a cell of row 2 (traffic revenue) and column 6 (maintenance) lists the DMUs $(1,35$, and 41) which are efficient in both the functional heads in the year 2015-2016. From Table 8, we realize Andaman \& Nicobar ST (DMU Sr. No. 3), Chandigarh TU (DMU Sr. No. 9), Navi Mumbai MT (DMU Sr.
No. 22), Odisha SRTC (DMU Sr. No. 26), and TN STC (Kumbakonam) Ltd. (DMU Sr. No. 37) are efficient in all functional heads except maintenance. Hence, in Table 9, these DMUs are present in all the cells except the ones which are under the maintenance column.

Similarly, we observe Thane MT (DMU Sr. No. 35) is efficient in all functional heads except vehicle operations (Table 8). Hence, Thane MT DMU is efficient for any two combinations of functional heads except the ones which involve vehicle operations (Table 9). The peers identified for each of the DMUs are shown in Table B4 (Appendix B of Supplementary Material).

4.4. Performance Analyses across Two Years. The above study (Sections 4.2, 4.2.1, 4.3, and 4.3.1) evaluated the performance of a DMU relative to other DMUs for the years 20142015 and 2015-2016. The consolidated results of the two years are shown in Table 10. From Table 10, we realize Thane MT and Navi Mumbai MT hold the top 2 ranks in both the years. However, Thane MT slipped to rank 2 (from rank 1 in the year 2014-2015) while Navi Mumbai MT raised to rank 1 in the year 2015-2016 (from rank 2 in the year 2014-2015).

Among all the DMUs, we observe the highest improvement in the rank of Ahmedabad MTC. The Ahmedabad MTC raise by 17 positions from rank 20 in the year 2014-2015 to rank 3 in the year 2015-2016. The observation from Table 10 is supported by the substantial improvement in the efficiency scores of Ahmedabad MTC (DMU Sr. No. 1) in Table 3 as compared with its efficiency scores in Table 2.

However, Table 10 reflects only upon the performance of a DMU relative to other DMUs for a given year. To see how the performance of a DMU has changed in the second year with respect to its own performance in the first year, in each of the functional heads, the Malmquist productivity change index $\left(M_{0}\right)$ was used. The base year for the study was 20142015. $M_{0}$ greater than 1 indicates an improvement over the base year, $M_{0}$ equal to 1 indicates the status quo, and $M_{0}$ less than 1 indicates worsening of performance. We calculated the final score by taking a weighted average of $M_{0}$ (weights obtained from AHP as earlier). The Malmquist indices of DMUs for the functional heads under consideration and their final score over the base year are shown in Table 11.

From Table 11, we observe that the Malmquist productivity change index $\left(M_{0}\right)$ of all the DMUs is greater than 1 , which indicates that all the DMUs have overall improved their performance in the year 2015-2016 with respect to their performance in the base year 2014-2015. The improvement in the "expenses" functional head, as evident from Table 11, primarily leads to the net improved performance of DMUs with respect to their performance in the last year. However, the performance of most of the DMUs has degraded in the "accident" functional head (Table 11) as the productivity change index is less than 1.

4.5. Sensitivity Analysis. We have performed the sensitivity analysis using the approach suggested by Triantaphyllou and Sanchez [29]. They have proposed two types of sensitivity 
TABLE 7: Categorization of DMUs by performance (year 2015-2016).

\begin{tabular}{|c|c|c|}
\hline Status & $Q$ score & DMUs \\
\hline $\begin{array}{l}\text { Very good } \\
\text { performers }\end{array}$ & $0 \leq Q \leq 0.2$ & $\begin{array}{c}\text { Navi Mumbai MT, Thane MT, Ahmedabad MTC, Odisha SRTC, Andaman \& Nicobar ST, Chandigarh } \\
\text { TU }\end{array}$ \\
\hline Good performers & $0.2<Q \leq 0.4$ & TN STC (Kumbakonam) Ltd., Meghalaya STC, Tripura RTC, Delhi TC, Sikkim NT \\
\hline $\begin{array}{l}\text { Average } \\
\text { performers }\end{array}$ & $0.4<Q \leq 0.6$ & $\begin{array}{c}\text { TN STC (Madurai) Ltd., State Exp.TC TN Ltd., BEST Undertaking, North Bengal STC, Calcutta STC, } \\
\text { TN STC (Salem) Ltd., Pune Mahamandal, Haryana ST, Bihar SRTC, J\&K SRTC, Kadamba TC Ltd., } \\
\text { Assam STC } \\
\end{array}$ \\
\hline Modest performers & $0.6<Q \leq 0.8$ & $\begin{array}{c}\text { TN STC (Coimbatore) Ltd., PUNBUS, Uttar Pradesh SRTC (P), State Transport Punjab, Nagaland ST, } \\
\text { Metro TC (Chennai) Ltd., Bangalore Metropolitan TC, South Bengal STC, Maharashtra SRTC(P), } \\
\text { Kerala SRTC, Karnataka SRTC, TN STC (Villupuram) Ltd., Rajasthan SRTC } \\
\end{array}$ \\
\hline Poor performers & $0.8<Q \leq 1$ & $\begin{array}{c}\text { Andhra Pradesh SRTC, Mizoram ST, North Western Karnataka RT, Gujarat SRTC, Telangana SRTC, } \\
\text { North Eastern Karnataka RT }\end{array}$ \\
\hline
\end{tabular}

TABle 8: Functional heads showing efficient DMUs (year 2015-2016).

\begin{tabular}{lcccccc}
\hline DMU & Accident & Traffic revenue & Expenses & Vehicle operations & Manpower & Maintenance \\
\hline Andaman \& Nicobar ST & $\checkmark$ & $\checkmark$ & $\checkmark$ & $\checkmark$ & $\checkmark$ & $\boldsymbol{x}$ \\
Chandigarh TU & $\checkmark$ & $\checkmark$ & $\checkmark$ & $\checkmark$ & $\checkmark$ & $\boldsymbol{x}$ \\
Navi Mumbai MT & $\checkmark$ & $\checkmark$ & $\checkmark$ & $\checkmark$ & $\checkmark$ & $\boldsymbol{x}$ \\
Odisha SRTC & $\checkmark$ & $\checkmark$ & $\sqrt{ }$ & $\checkmark$ & $\checkmark$ \\
Thane MT & $\checkmark$ & $\checkmark$ & $\checkmark$ & $\checkmark$ & $\boldsymbol{x}$ \\
TN STC (Kumbakonam) Ltd. & $\checkmark$ & $\checkmark$ & $\checkmark$ & $\checkmark$ \\
Tripura RTC & $\checkmark$ & $\checkmark$ & $\checkmark$ & $\checkmark$ \\
\hline
\end{tabular}

TABle 9: Set of efficient DMUs (year 2015-2016).

\begin{tabular}{|c|c|c|c|c|c|c|}
\hline & Accident & Traffic revenue & Expenses & Vehicle operations & Manpower & Maintenance \\
\hline \multirow[t]{6}{*}{ Accident } & $\begin{array}{c}1,3,4,7,8,9,18, \\
20,21,22,26,31, \\
35,37,38,39,40, \\
41,42\end{array}$ & $\begin{array}{c}1,3,4,9,22,26,35,37 \\
38,39,40,41,42\end{array}$ & $\begin{array}{c}1,3,8,9,18,20 \\
22,26,31,35 \\
37,41\end{array}$ & $\begin{array}{c}3,7,9,18,20,21,22,26 \\
31,37,38,39,40,41,42\end{array}$ & $\begin{array}{c}3,9,18,22,26,35 \\
37,38,39,40,42\end{array}$ & $\begin{array}{c}1,8,20,35 \\
41\end{array}$ \\
\hline & Traffic revenue & $\begin{array}{c}1,2,3,4,5,6,9,10,12, \\
13,15,16,17,19,22,23 \\
25,26,27,28,29,33,34 \\
35,36,37,38,39,40,41 \\
42\end{array}$ & $\begin{array}{l}1,3,9,10,22 \\
26,35,37,41\end{array}$ & $\begin{array}{c}2,3,5,6,9,10,13,16,17 \\
19,22,23,26,27,28,29 \\
33,34,36,37,38,39,40 \\
41,42\end{array}$ & $\begin{array}{c}3,9,19,22,23,26 \\
28,34,35,36,37,38 \\
39,40,42\end{array}$ & $1,35,41$ \\
\hline & & Expenses & $\begin{array}{c}1,3,8,9,10,18 \\
20,22,26,31 \\
35,37,41\end{array}$ & $\begin{array}{c}3,9,10,18,20,22,26,31 \\
37,41\end{array}$ & $\begin{array}{c}3,9,18,22,26,35 \\
37\end{array}$ & $\begin{array}{c}1,8,20,35 \\
41\end{array}$ \\
\hline & & & $\begin{array}{l}\text { Vehicle } \\
\text { Operations }\end{array}$ & $\begin{array}{l}2,3,5,6,7,9,10,13,16 \\
17,18,19,20,21,22,23 \\
26,27,28,29,31,33,34 \\
36,37,38,39,40,41,42\end{array}$ & $\begin{array}{c}3,9,18,19,22,23 \\
26,28,34,36,37,38 \\
39,40,42\end{array}$ & 20,41 \\
\hline & & & & Manpower & $\begin{array}{c}3,9,18,19,22,23 \\
26,28,34,35,36,37 \\
38,39,40,42\end{array}$ & 35 \\
\hline & & & & & Maintenance & $\begin{array}{c}1,8,20,35 \\
41\end{array}$ \\
\hline
\end{tabular}

measures-Absolute Top (AT) or Percentage Top (PT) and Absolute Any (AA) or Percentage Any (PA). AT is defined as the smallest change in the weight of criteria which will result in a change in the rank of the topmost DMU. Similarly, AA is defined as the smallest change in the weight which will lead to a change in the rank of any of the DMUs. Our analysis is concerned with finding out the top performing DMUs so that the other DMUs can adopt its best practices and improve their performance. Hence, we focus on finding AT and PT only.

For the year 2014-2015, Thane MT achieves an efficiency of 1 in all the criteria, and hence the sensitivity coefficient comes out to be 0 . For the year 2015-2016, none of the DMUs achieve an efficiency of 1 in all the criteria; vehicle operations come out to be the most sensitive criteria with a sensitivity coefficient of 1.149, followed by maintenance with a 
TABLE 10: Rank of DMUs across years.

\begin{tabular}{|c|c|c|c|}
\hline DMU & Rank in $2014-2015$ & Rank in $2015-2016$ & Change in rank \\
\hline Ahmedabad MTC & 20 & 3 & $17 \uparrow$ \\
\hline Andhra Pradesh SRTC & 39 & 37 & $2 \uparrow$ \\
\hline Andaman \& Nicobar ST & 5 & 5 & Status quo $<\Rightarrow$ \\
\hline Assam STC & 15 & 23 & $8 \downarrow$ \\
\hline BEST Undertaking & 12 & 14 & $2 \downarrow$ \\
\hline Bangalore Metropolitan TC & 34 & 30 & $4 \uparrow$ \\
\hline Bihar SRTC & 29 & 20 & $9 \uparrow$ \\
\hline Calcutta STC & 7 & 16 & $9 \sqrt{2}$ \\
\hline Chandigarh TU & 4 & 6 & $2 \downarrow$ \\
\hline Delhi TC & 11 & 10 & $1 \uparrow$ \\
\hline Gujarat SRTC & 40 & 40 & Status quo $<\Rightarrow$ \\
\hline Haryana ST & 10 & 19 & $9 \downarrow$ \\
\hline J\&K SRTC & 14 & 21 & $7 \downarrow$ \\
\hline Kadamba TC Ltd. & 21 & 22 & $1 \downarrow$ \\
\hline Karnataka SRTC & 26 & 34 & $8 \downarrow$ \\
\hline Kerala SRTC & 35 & 33 & $2 \uparrow$ \\
\hline Maharashtra SRTC(P) & 32 & 32 & Status quo $<$ \\
\hline Meghalaya STC & 19 & 8 & $11 \uparrow$ \\
\hline Metro TC (Chennai) Ltd. & 23 & 29 & $6 \Downarrow$ \\
\hline Mizoram ST & 37 & 38 & $1 \downarrow$ \\
\hline Nagaland ST & 30 & 28 & $2 \uparrow$ \\
\hline Navi Mumbai MT & 2 & 1 & $1 \uparrow$ \\
\hline North Bengal STC & 27 & 15 & $12 \uparrow$ \\
\hline North Eastern Karnataka RT & 38 & 42 & $4 \Downarrow$ \\
\hline North Western Karnataka RT & 36 & 39 & $3 \downarrow$ \\
\hline Odisha SRTC & 3 & 4 & $1 \Downarrow$ \\
\hline Pune Mahamandal & 33 & 18 & $15 \uparrow$ \\
\hline PUNBUS & 25 & 25 & Status quo $<\Rightarrow$ \\
\hline State Transport Punjab & 28 & 27 & $1 \uparrow$ \\
\hline Rajasthan SRTC & 24 & 36 & $12 \downarrow$ \\
\hline Sikkim NT & 9 & 11 & $2 \Downarrow$ \\
\hline South Bengal STC & 42 & 31 & $11 \uparrow$ \\
\hline State Exp.TC TN Ltd. & 16 & 13 & $3 \uparrow$ \\
\hline Telangana SRTC & 41 & 41 & Status quo $<\Rightarrow$ \\
\hline Thane MT & 1 & 2 & $1 \downarrow$ \\
\hline TN STC (Coimbatore) Ltd. & 22 & 24 & $2 \downarrow$ \\
\hline TN STC (Kumbakonam) Ltd. & 6 & 7 & $1 \downarrow$ \\
\hline TN STC (Madurai) Ltd. & 8 & 12 & $4 \downarrow$ \\
\hline TN STC (Salem) Ltd. & 13 & 17 & $4 \downarrow$ \\
\hline TN STC (Villupuram) Ltd. & 31 & 35 & $4 \downarrow$ \\
\hline Tripura RTC & 17 & 9 & $8 \uparrow$ \\
\hline Uttar Pradesh SRTC $(\mathrm{P})$ & 18 & 26 & $8 \downarrow$ \\
\hline
\end{tabular}

sensitivity coefficient of 0.697 (Table 12). A high sensitivity coefficient (typically greater than 5 ) indicates low stability; hence, our results are stable.

\section{Discussions}

The results of the study can be broadly viewed from two aspects. First, the relative performance of a DMU with respect to other DMUs in a particular year (Tables 2-9) is evaluated. This evaluation was done for two consecutive years, i.e., the year 2014-2015 and the year 2015-2016, and we observe the change in the rank of DMUs (Table 10). Second, the performance of all the DMUs in the second year with respect to their own performance in the first year (Table 11) is evaluated.

The inferences drawn from the first aspect of results are as follows: (a) Thane MT, Navi Mumbai MT, Odisha SRTC, and Chandigarh TU were consistently very good performers in both the years (Tables 4 and 7)

(b) Gujarat SRTC and Telangana SRTC were consistently poor performers in both the years (Tables 4 and 7)

The inferences drawn from the second aspect of results are as follows:

(a) The performance of all the DMUs has improved in the year 2015-2016 with respect to the year 20142015. The $M_{0}$ of all the DMUs is greater than 1 (Table 11).

(b) There was a substantial improvement in the "expenses" functional head with average $M_{0}=2.785$ (Table 11). The "expenses" functional head carries higher priority 
TABLE 11: Malmquist productivity change index of DMUs.

\begin{tabular}{|c|c|c|c|c|c|c|c|}
\hline DMU & Accident & Traffic revenue & Expenses & Vehicle operations & Manpower & Maintenance & $M_{0}$ \\
\hline Ahmedabad MTC & 1.028 & 1.031 & 3.817 & 0.987 & 1.022 & 1.319 & 1.774 \\
\hline Andhra Pradesh SRTC & 0.849 & 0.972 & 2.624 & 0.92 & 0.864 & 0.795 & 1.345 \\
\hline Andaman \& Nicobar ST & 0.916 & 0.834 & 2.984 & 0.938 & 0.859 & 0.981 & 1.430 \\
\hline Assam STC & 0.755 & 1.132 & 2.615 & 1.017 & 0.826 & 0.715 & 1.375 \\
\hline BEST Undertaking & 0.83 & 0.992 & 2.797 & 0.947 & 0.875 & 0.805 & 1.400 \\
\hline Bangalore Metropolitan TC & 0.792 & 1.063 & 2.937 & 1.038 & 0.691 & 0.76 & 1.430 \\
\hline Bihar SRTC & 0.854 & 0.947 & 2.834 & 1.033 & 1.246 & 0.825 & 1.471 \\
\hline Calcutta STC & 0.903 & 0.895 & 2.943 & 0.761 & 0.776 & 0.941 & 1.393 \\
\hline Chandigarh TU & 0.86 & 1.061 & 2.901 & 1.048 & 1.21 & 0.743 & 1.505 \\
\hline Delhi TC & 0.841 & 0.958 & 2.874 & 0.94 & 0.96 & 0.845 & 1.428 \\
\hline Gujarat SRTC & 0.83 & 0.957 & 2.681 & 0.974 & 0.939 & 0.821 & 1.376 \\
\hline Haryana ST & 0.769 & 1.029 & 2.374 & 1.003 & 0.978 & 0.732 & 1.310 \\
\hline J\&K SRTC & 0.761 & 0.94 & 2.819 & 0.897 & 0.796 & 0.942 & 1.382 \\
\hline Kadamba TC Ltd. & 0.834 & 1.021 & 2.797 & 0.953 & 1.03 & 0.816 & 1.433 \\
\hline Karnataka SRTC & 0.786 & 0.926 & 2.469 & 0.99 & 0.87 & 0.76 & 1.294 \\
\hline Kerala SRTC & 0.897 & 1.001 & 2.827 & 0.924 & 0.942 & 0.954 & 1.439 \\
\hline Maharashtra SRTC(P) & 0.84 & 0.972 & 2.845 & 0.965 & 0.907 & 0.859 & 1.421 \\
\hline Meghalaya STC & 0.821 & 1.164 & 2.733 & 1.162 & 1.142 & 0.758 & 1.492 \\
\hline Metro TC (Chennai) Ltd. & 0.823 & 0.948 & 2.667 & 0.991 & 0.905 & 0.802 & 1.365 \\
\hline Mizoram ST & 0.737 & 0.866 & 2.885 & 0.83 & 0.587 & 0.737 & 1.314 \\
\hline Nagaland ST & 0.835 & 0.951 & 2.675 & 1.217 & 1.005 & 0.676 & 1.401 \\
\hline Navi Mumbai MT & 0.894 & 1.056 & 2.906 & 0.929 & 0.962 & 0.945 & 1.476 \\
\hline North Bengal STC & 0.831 & 1.206 & 2.839 & 1.037 & 1.341 & 0.835 & 1.553 \\
\hline North Eastern Karnataka RT & 0.825 & 0.952 & 2.704 & 0.997 & 0.819 & 0.833 & 1.366 \\
\hline North Western Karnataka RT & 0.797 & 0.957 & 2.541 & 0.999 & 0.921 & 0.776 & 1.333 \\
\hline Odisha SRTC & 0.823 & 1.028 & 2.559 & 1.03 & 1.079 & 0.801 & 1.389 \\
\hline Pune Mahamandal & 0.835 & 1.06 & 2.803 & 0.963 & 0.93 & 0.88 & 1.438 \\
\hline PUNBUS & 0.869 & 0.959 & 2.746 & 1.031 & 0.924 & 0.895 & 1.410 \\
\hline State Transport Punjab & 0.86 & 0.976 & 2.819 & 0.927 & 1.133 & 0.83 & 1.444 \\
\hline Rajasthan SRTC & 0.764 & 0.991 & 2.445 & 0.974 & 0.93 & 0.748 & 1.309 \\
\hline Sikkim NT & 0.814 & 1.108 & 2.742 & 0.843 & 0.8 & 1.061 & 1.416 \\
\hline South Bengal STC & 0.834 & 1.028 & 2.799 & 1.118 & 1.19 & 0.846 & 1.486 \\
\hline State Exp.TC TN Ltd. & 0.891 & 0.982 & 2.9 & 0.941 & 1.044 & 0.894 & 1.464 \\
\hline Telangana SRTC & 0.836 & 0.901 & 2.687 & 0.936 & 0.839 & 0.794 & 1.340 \\
\hline Thane MT & 0.788 & 0.901 & 2.611 & 0.925 & 0.864 & 0.73 & 1.312 \\
\hline TN STC (Coimbatore) Ltd. & 0.834 & 0.971 & 2.747 & 0.971 & 0.934 & 0.854 & 1.399 \\
\hline TN STC (Kumbakonam) Ltd. & 0.794 & 0.9 & 2.777 & 0.916 & 0.886 & 0.82 & 1.367 \\
\hline TN STC (Madurai) Ltd. & 0.828 & 0.961 & 2.775 & 0.956 & 0.901 & 0.859 & 1.397 \\
\hline TN STC (Salem) Ltd. & 0.827 & 0.739 & 2.751 & 0.95 & 0.55 & 0.867 & 1.279 \\
\hline TN STC (Villupuram) Ltd. & 0.795 & 0.935 & 2.606 & 0.938 & 0.923 & 0.812 & 1.340 \\
\hline Tripura RTC & 1.022 & 0.732 & 3.689 & 0.711 & 2.217 & 1.029 & 1.778 \\
\hline Uttar Pradesh SRTC $(\mathrm{P})$ & 0.793 & 0.895 & 2.459 & 0.962 & 0.998 & 0.759 & 1.300 \\
\hline Average $\left(M_{0}\right)$ & 0.836 & 0.973 & 2.785 & 0.966 & 0.967 & 0.844 & 1.413 \\
\hline
\end{tabular}

TABLE 12: Sensitivity coefficients for weights of different functional heads.

\begin{tabular}{lcccccc}
\hline \multirow{2}{*}{ Analysis year } & \multicolumn{4}{c}{ Sensitivity coefficients } \\
& Accident & Traffic revenue & Expenses & Vehicle operations & Manpower & Maintenance \\
\hline $2014-2015$ & NA & NA & NA & NA & NA & NA \\
$2015-2016$ & NA & NA & NA & $\mathbf{1 . 1 4 9}$ & NA & $\mathbf{0 . 6 9 7}$ \\
\hline
\end{tabular}

with weight $=0.258$ (Tables 2 and 3 ) for the DMUs, and the DMUs have performed well on this front.

(c) There is a scope for improvement in other functional heads. For instance, the Uttar Pradesh SRTC (P) appears to have performed well only in the "expenses" front with $M_{0}=2.459$ (Table 10). However, it has not performed well on the other parameters, eventually leading to a drop in the overall ranking by 8 points (Table 10 ).

(d) The top performing DMU like Thane MT has slipped to the second position in the second year. The Malmquist productivity change index indicates that 
there is scope for improvement in the "accident" head $\left(M_{0}=0.788\right)$ and "maintenance" head $\left(M_{0}=0.73\right)$. A similar analysis can be carried out for all the other DMUs to identify their scope for further improvement.

Also, the results show that in the certain functional head (like accident), only a couple of DMUs have improved, and the performance of all others has worsened as the value of the productivity change index is less than 1 (Table 11). This highlights the need for strategic action plans/policy interventions to improve the existing situation.

A number of studies in Indian context have tried to evaluate the performance of the public road transportation system in a particular state or city. While a study [40] identifies the top cities in India for public transportation, Badami and Haider [41] use an analytical framework to determine the transit performance of public buses in Indian cities. Our study extends the geographical scope of analysis and identifies the top performing public road transportation systems across the country using a comprehensive methodology thereby making the results more robust.

\section{Conclusions}

In this paper, we considered twenty-three criteria to evaluate the relative performance of forty-two major road transportation organizations in India. We integrated four MCDM techniques (AHP, DEA, VIKOR, and MPI) to establish the relative importance of functional heads, compute efficiency scores of DMUs for the classified heads, assign ranks to DMUs based on efficiency scores and relative importance of functional heads, and evaluate interyear performance of DMUs. We realize that all the DMUs have performed better in the second year with respect to their performance in the first year. We identify the functional head in which significant improvement is observed in the performance of all the DMUs. We also identify the best performing DMUs and realize few DMUs have been consistently very good performers in both the years. However, there were also few DMUs which have poorly performed in both the years. We further observe, in the "accident" functional head, the performance of the majority of DMUs has deteriorated. The state government/ local municipal corporations can build upon these observations and take necessary steps to enhance the efficiency of their respective road transport corporation. This study also identifies the best-performing DMUs which can be used for benchmarking and sharing key learnings among the DMUs. Currently, the Ministry of Urban Development, Government of India, uses a benchmarking manual to identify key performance indicators and carry out the performance evaluation. The benchmarking manual [42] states the data collection approach and the methodology to be used for performance evaluation. Such a method is time consuming and inefficient. Our study proposes to identify the top performing DMUs in a more adroit manner and uses their best practices. This can help policy makers make quick decisions which are also more reliable.
The limitation of this study is that few qualitative/ quantitative criteria like cleanliness, staff behavior to customer, punctuality, on-board security, and on-time arrival/ departure have not been considered in the evaluation of the performance. The future scope of the study lies in incorporating these criteria into consideration for a more exhaustive evaluation of the same. Future studies may explore the usage to other MCDM tools like stochastic DEA (SDEA), fuzzy DEA (FDEA), and imprecise DEA (IDEA) to accommodate qualitative criteria discussed above. Other MCDM tools like TOPSIS, DEMATEL, ELECTRE, and PROMETHEE may be explored to develop an evaluation scheme to validate/verify the findings of this study.

\section{Data Availability}

The data used in this study were drawn from the Ministry of Road Transport and Highways, Government of India, accessed on October 15, 2019. Any other additional derived data used to support the findings of the study are available from the corresponding author upon request (http://morth. nic.in/sites/default/files/Review_2015_2016.pdf).

\section{Conflicts of Interest}

The authors declare there are no conflicts of interest.

\section{Supplementary Materials}

The supplementary material consists of an appendix that contains details of DMUs (Appendix A), base data (Tables B1 and B2 of Appendix B), set of peer DMUs (Tables B3 and B4 of Appendix B), and description of criteria for evaluation (Appendix C). Tables B1, B2, B3, and B4 are available in the supplementary excel file. (Supplementary Materials)

\section{References}

[1] Ministry of Road Transport and Highways, The Government of India, Review of the Performance of State Road Transport Undertakings, Ministry of Road Transport and Highways, The Government of India, New Delhi, India, 2019, http://morth. nic.in/sites/default/files/Review_2015_2016.pdf.

[2] J. A. Annema, N. Mouter, and J. Razaei, "Cost-benefit analysis (CBA), or multi-criteria decision-making (MCDM) or both: politicians' perspective in transport policy appraisal," Transportation Research Procedia, vol. 10, pp. 788-797, 2015.

[3] P. J. G. Pineda, J. J. H. Liou, C.-C. Hsu, and Y.-C. Chuang, "An integrated MCDM model for improving airline operational and financial performance," Journal of Air Transport Management, vol. 68, pp. 103-117, 2018.

[4] J. C. Pérez, M. H. Carrillo, and J. R. Montoya-Torres, "Multicriteria approaches for urban passenger transport systems: a literature review," Annals of Operations Research, vol. 226, no. 1, pp. 69-87, 2015.

[5] L. Cruz, E. Barata, and J. P. Ferreira, "Performance in urban public transport systems: a critical analysis of the Portuguese case," International Journal of Productivity and Performance Management, vol. 61, no. 7, pp. 730-751, 2012.

[6] J. Holmgren, "The efficiency of public transport operations-an evaluation using stochastic frontier analysis," 
Research in Transportation Economics, vol. 39, no. 1, pp. 5057, 2013.

[7] O. Vaidya, "Evaluating the performance of public urban transportation systems in India," Journal of Public Transportation, vol. 17, no. 4, pp. 174-191, 2014.

[8] P. Saxena, "A benchmarking strategy for Delhi transport corporation: an application of data envelopment analysis," International Journal of Mathematical, Engineering and Management Sciences, vol. 4, no. 1, pp. 232-244, 2019.

[9] S. Chakraborty, R. Ranjan, and P. Mondal, "A state-wise performance appraisal of the Indian roads using PROMETHEE-GIS approach," Benchmarking: An International Journal, vol. 25, no. 9, pp. 3338-3356, 2018.

[10] R. Ranjan, P. Chatterjee, and S. Chakraborty, "Performance evaluation of Indian Railway zones using DEMATEL and VIKOR methods," Benchmarking: An International Journal, vol. 23, no. 1, pp. 78-95, 2016.

[11] Y. Hawas, M. Khan, and N. Basu, "Evaluating and enhancing the operational performance of public bus systems using GISbased data envelopment analysis," Journal of Public Transportation, vol. 15, no. 2, pp. 19-44, 2012.

[12] J.-S. Hahn, D.-K. Kim, H.-C. Kim, and C. Lee, "Efficiency analysis on bus companies in Seoul city using a network DEA model," KSCE Journal of Civil Engineering, vol. 17, no. 6, pp. 1480-1488, 2013.

[13] V. S. Rodrigues, J. Cowburn, A. Potter, M. Naim, and A. Whiteing, "Developing "extra distance" as a measure for the evaluation of road freight transport performance," International Journal of Productivity and Performance Management, vol. 63, no. 7, pp. 822-840, 2014.

[14] C. Macharis, A. De Witte, and J. Ampe, "The multi-actor, multi-criteria analysis methodology (MAMCA) for the evaluation of transport projects: theory and practice," Journal of Advanced Transportation, vol. 43, no. 2, pp. 183-202, 2009.

[15] M. Ignaccolo, G. Inturri, M. García-Melón, N. Giuffrida, M. Le Pira, and V. Torrisi, "Combining analytic hierarchy process (AHP) with role-playing games for stakeholder engagement in complex transport decisions," Transportation Research Procedia, vol. 27, pp. 500-507, 2017.

[16] O. Ghorbanzadeh, S. Moslem, T. Blaschke, and S. Duleba, "Sustainable urban transport planning considering different stakeholder groups by an interval-AHP decision support model," Sustainability, vol. 11, no. 1, p. 9, 2019.

[17] S. Moslem, O. Ghorbanzadeh, T. Blaschke, and S. Duleba, "Analysing stakeholder consensus for a sustainable transport development decision by the fuzzy AHP and interval AHP," Sustainability, vol. 11, no. 12, p. 3271, 2019.

[18] N. Giuffrida, M. Le Pira, G. Inturri, and M. Ignaccolo, "Mapping with stakeholders: an overview of public participatory GIS and VGI in transport decision-making," ISPRS International Journal of Geo-Information, vol. 8, no. 4, p. 198, 2019.

[19] M. Ignaccolo, G. Inturri, N. Giuffrida, M. L. Pira, and V. Torrisi, "Public engagement for designing new transport services: investigating citizen preferences from a multiple criteria perspective," Transportation Research Procedia, vol. 37, pp. 91-98, 2019.

[20] S. Duleba and S. Moslem, "Examining pareto optimality in analytic hierarchy process on real data: an application in public transport service development," Expert Systems with Applications, vol. 116, pp. 21-30, 2019.

[21] S. Moslem, A. Alkharabsheh, K. Ismael, and S. Duleba, "An integrated decision support model for evaluating public transport quality," Applied Sciences, vol. 10, no. 12, p. 4158, 2020.

[22] M. E. Lopez Lambas and N. Giuffrida, "Comparison between bus rapid transit and light-rail transit systems: a multi-criteria decision analysis approach," Urban Transport XXIII, vol. 176, no. 143, 2017.

[23] M. Nassereddine and H. Eskandari, "An integrated MCDM approach to evaluate public transportation systems in Tehran," Transportation Research Part A: Policy and Practice, vol. 106, pp. 427-439, 2017.

[24] I. M. García Sánchez, "Technical and scale efficiency in Spanish urban transport: estimating with data envelopment analysis," Advances in Operations Research, vol. 2009, Article ID 721279, 15 pages, 2009.

[25] M. Gonçalves de Carvalho Wolff and M. Antonio Farah Caldas, "A model for the evaluation of brazilian road transport: a sustainable perspective," Journal of Advanced Transportation, vol. 2018, Article ID 5274789, 12 pages, 2018.

[26] C. Sun, X. Chen, H. M. Zhang, and Z. Huang, "An evaluation method of urban public transport facilities resource supply based on accessibility," Journal of Advanced Transportation, vol. 2018, Article ID 3754205, 11 pages, 2018.

[27] T. L. Saaty, The Analytic Hierarchy Process, McGraw-Hill, New York, NY, USA, 1980.

[28] O. S. Vaidya and S. Kumar, "Analytic hierarchy process: an overview of applications," European Journal of Operational Research, vol. 169, no. 1, pp. 1-29, 2006.

[29] E. Triantaphyllou and A. Sánchez, “A sensitivity analysis approach for some deterministic multi-criteria decisionmaking methods," Decision Sciences, vol. 28, no. 1, pp. 151-194, 1997.

[30] M. J. Farrell, "The measurement of productive efficiency," Journal of the Royal Statistical Society. Series A (General), vol. 120, no. 3, pp. 253-281, 1957.

[31] A. Charnes, W. W. Cooper, and E. Rhodes, "Measuring the efficiency of decision making units," European Journal of Operational Research, vol. 2, no. 6, pp. 429-444, 1978.

[32] L. Duckstein and S. Opricovic, "Multiobjective optimization in river basin development," Water Resources Research, vol. 16, no. 1, pp. 14-20, 1980.

[33] S. Opricovic and G.-H. Tzeng, "Compromise solution by MCDM methods: a comparative analysis of VIKOR and TOPSIS," European Journal of Operational Research, vol. 156, no. 2, pp. 445-455, 2004.

[34] P. L. Yu, "A class of solutions for group decision problems," Management Science, vol. 19, no. 8, pp. 936-946, 1973.

[35] M. Zeleny, Multiple Criteria Decision Making, McGraw-Hill Company, New York, NY, USA, 1982.

[36] S. Malmquist, "Index numbers and indifference surfaces," Trabajos de Estadistica, vol. 4, no. 2, pp. 209-242, 1953.

[37] R. Färe, S. Grosskopf, M. Norris, and Z. Zhang, "Productivity growth, technical progress, and efficiency change in industrialized countries," The American Economic Review, vol. 84, no. 1, pp. 66-83, 1994.

[38] A. I. Ali and L. M. Seiford, "Translation invariance in data envelopment analysis," Operations Research Letters, vol. 9, no. 6, pp. 403-405, 1990.

[39] Centre for Efficiency and Productivity Analysis, The University of Queensland, Australia, 2019, http://www.uq.edu.au/ economics/cepa/deap.php.

[40] Arthur D. Little future Labs, Future of urban mobility 2.0, https://www.adlittle.com/sites/default/files/viewpoints/2014_ ADL_UITP_Future_of_Urban_Mobility_2_0_Full_study. pdf. 
[41] M. G. Badami and M. Haider, "An analysis of public bus transit performance in Indian cities," Transportation Research Part A: Policy and Practice, vol. 41, no. 10, pp. 961-981, 2007.

[42] Ministry of Urban Development, Government of India, Service Level Benchmark in Urban Transport for Indian Cities, Ministry of Urban Development, Government of India, New Delhi, India, 2020, http://mohua.gov.in/upload/uploadfiles/ files/VoulmeI_Methodologyreport_final03.pdf. 